\title{
THE DESIGN AND FABRICATION OF CRUSHING MACHINE
}

\section{USING DOUBLE TOGGLE MECHANISM}

\section{ANTONY IMMANUEL AKASH, M. GANESH RAJ, V. KUMARESH, S. BHARATH KUMAR \& P. RAGHU}

Department of Mechanical Engineering, Sri Venkateswara College of Engineering,

Pennalur, Sriperumbudur, Tamil Nadu, India

\begin{abstract}
A simple comprehensive method is proposed for the design of a double toggle mechanism for crushing machine. In the proposed approach method, the crushing operation was performed with crushing tool and its simultaneously working. It is easy to perform the number of crushing operation in a single drive motor system it can be replace the crushing tool. The numerical simulation is carried out by using commercially available CFD software named ANSYS12.1 and the results are presented. Finally, a toggle mechanism is fabricated in order to demonstrate the feasibility of the proposed approach and number of punching in single drive and time interval system.

KEYWORDS: Crushing Tool, Double Toggle, Linkage, ANSYS12.1, Magnifying Input Loads \& Single Drive System
\end{abstract}

Received: Sep 18, 2018; Accepted: Oct 12, 2018; Published: Nov 14, 2018; Paper Id.: IJIETDEC20182

\section{INTRODUCTION}

Toggle mechanisms are usually used within linkages and serve lots of purposes. The function is to transfer rotational motion into linear motion, magnify input loads and to lock the position of the linkage. During this transfer, the links within a toggle mechanism are subjected to a lot of stress, especially when it is intended to lock the position of a linkage.

During the toggle position as the toggle mechanism passes, all the links get dense thus producing a large amount of force within it. This mechanism consists of two links, a slide, a stop, and three connecting pins. The two links are able to rotate about their connecting pins and the slide allows translational movement during this evaluation, the pin is pushed vertically downward forcing the other two links to rotate about their endpoints and the slide to translate towards the right.

When the pin is pushed a adequate distance, such that the adjacent links are united, the mechanism is said to be at its "toggle" point. At this position the components within the linkage have experienced their maximum compression and therefore their maximum amount of load. As the mechanism goes past this point, around is an indulgence of loads within the linkages and it is said to travel over-toggle. Frequently this over-toggle location is used, all along with a solid end for the links, this is finished to assure that linkage is protected in position while any forces from the outer pins would go the middle pin further down and into the potential hard stop. In addition, because of the huge forces experienced within a toggle mechanism, there is a component that is compliant and takes some of the stress formed by the intrusion between the links as they pass into the over-toggle position. In addition, the compliant material also provides a constant force back into the linkage serving lock it into 
the over-toggle position.

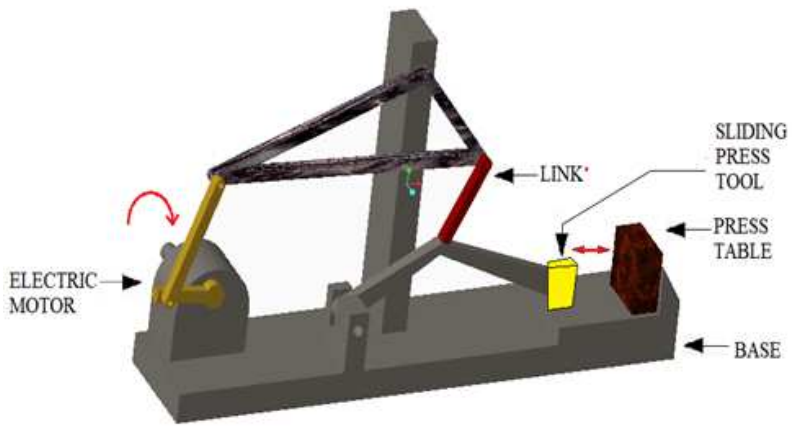

Figure 1: Double Toggle Mechanism

\section{EXPERIMENTAL SETUP AND WORKING PRINCIPLE}

Toggle mechanisms are commonly used within linkages and serve many purposes. One of its reason is to transmit rotational motion of the motor into to and fro motion, thereby reproduce input loads (since a toggle mechanism afford the essential mechanical improvement), and locking the position of a linkage.

In all of these applications, the links within a toggle mechanism experience a great deal of stress, especially when used to lock the position of a linkage. As the toggle device passes through the toggle position, each of the links are condensed from a large quantity of force inside the linkage. This mechanism consists of two links, a slide, a stop, and three connecting pins.

The two links are able to rotate about their connecting pins and the slide allowed translational movement, during this evaluation, the pin is pushed vertically downward forcing the other two links to rotate about their endpoints and the slide to translate towards the right.

While the pin is pressed a sufficient distance, such that the neighbouring links are aligned, the method is said to be at its "toggle" point. At this position the components within the linkage have experienced their greatest compression and therefore their greatest amount of load.

As the system goes ahead of this point, there is a dissipation of loads inside the linkages and it is said to pass through over-toggle. Frequently this over-toggle location is used, beside with a durable end for the links, this is finished to make sure that linkage has been protected in place since any forces from the outer pins would progress the middle pin further down and into the potential hard stop. Additionally, there is a deferential module that obtains some of the stress shaped by the intrusion, due to the forces practised within a toggle method, between the links as they pass into the over-toggle position. Additionally, the compliant material also provides a constant force back into the linkage helping lock it into the over-toggle position. This model uses a double toggle mechanism which is fully linked based system, which is driven by the single motor drive within a rigid link connection.

The complete revolution of crank lever to facilitate is linked to a motor which turn at a particular speed (rpm) translate the rotating motion into to and fro action on press instrument using double toggle method.

- This representation consists of six links, in whole, initially by means of motor crank linkage.

- Next linkage joins mutually as the stiff link and the press tool. 
- Third link acting on rigid link.

- Fourth is connecting on second and third one.

- Then fifth link connecting another one of rigid link.

- Sixth one is connecting on press tool.

\section{Numerical Simulations}

\section{Numerical Mesh}

The first important task in the process of simulation is the creation of a computational mesh to represent the flow domain geometry. The numerical simulation is carried out by using commercially available CFD software named Ansys and was shown in figure 2. The dimensions of numerical mesh were shown in Table 1. The mesh generalize are

- $\quad$ Aspect Ratio - 1:2

- Height of the can -20 elements

- Circumference of the can -10 elements

- Model Defined for Can - Shell in nature

- Model defined for Rigid Wall - solid

Table 1: Dimensions Were Drawn From Coca Cola Soda Can

\begin{tabular}{|l|c|}
\hline Height & 12.1 centimeters \\
\hline Radius & 3.3 centimeters \\
\hline Thickness & 0.25 centimeters \\
\hline Thickness on lid of the can & 0.3 centimeters \\
\hline Thickness on the bottom of the can & 0.3 centimeters \\
\hline
\end{tabular}

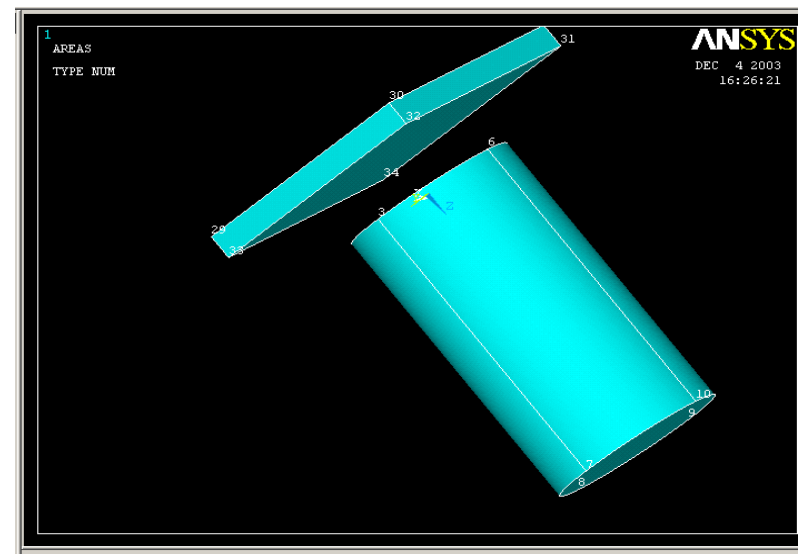

Figure 2: 3-D View Showing Can and Rigid Dimensions Wall

\section{RESULTS AND DISCUSSIONS}

From the numerical simulation the results are presented as in Table. The Crush of the Soda Can was occurred at following Values and results are presented in the Figures 3 to 9.and values are shown in the Table 2. 
Table 2: Numerical Simulation Results

\begin{tabular}{|l|l|}
\hline Von mises Stress & 7.652E+9 Pascal. \\
\hline Pressure & $3.426 \mathrm{E}+9$ Pascal. \\
\hline Z- Stress & 7.42E+9 Pascal. \\
\hline Z- Displacement & 0.07425 meter \\
\hline Time step & 0.00053 sec. \\
\hline X- displacement & $-9.0 \mathrm{e}-7$ meters \\
\hline
\end{tabular}

The design of the double-toggle clamping mechanism for which the high performance of the can crushing machine could not be realized. In this paper, aimed to the design of the can crushing machine, based on the analysis of the motion feature, the multi-body dynamics equation was constructed, and the various propose factor in the model were examined by ANSYS software. From the result, after optimized, it was found that the Von mises stress was $7.652 \mathrm{E}+9$ pascal, because per the design scheme, with mathematical simulation the force was calculated, and from the consequence, the needs of the design were realized.

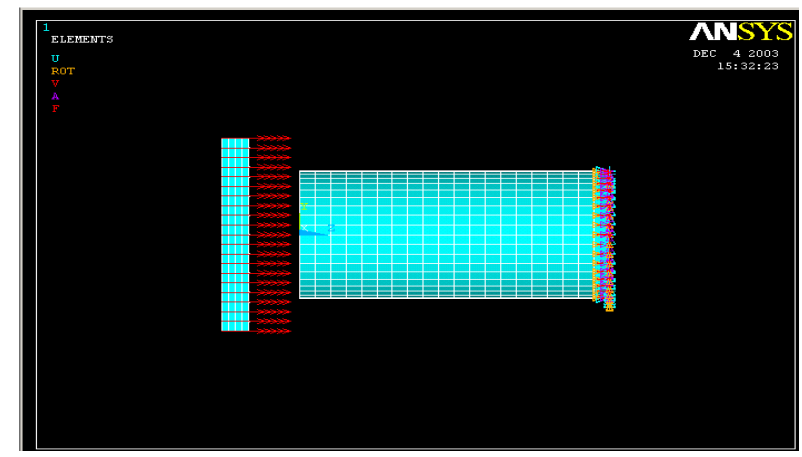

Figure 3: Isometric View Showing

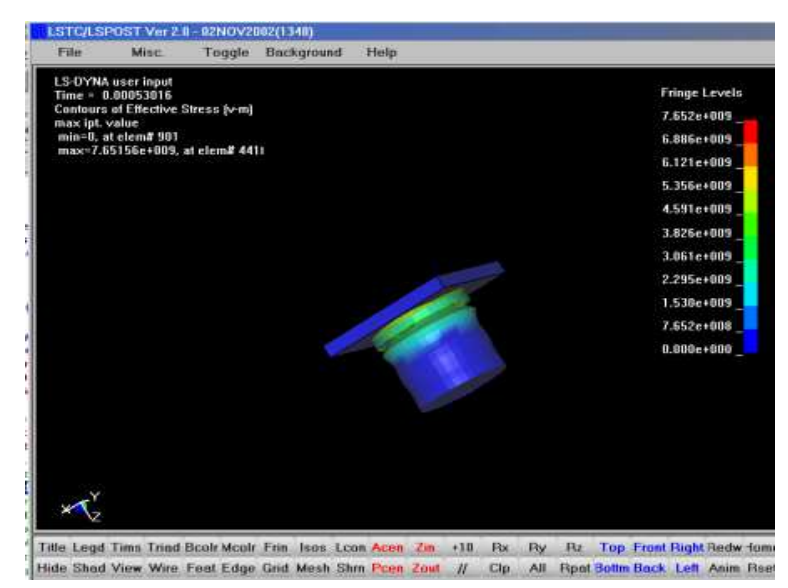

Figure 5: Pressure

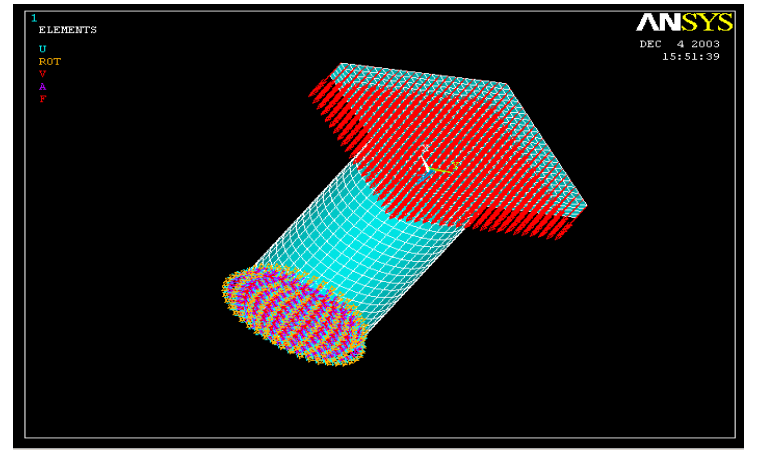

Figure 4: Isometric View with Force on Rigid wall and constraint on the bottom of the can All the Applied Conditions

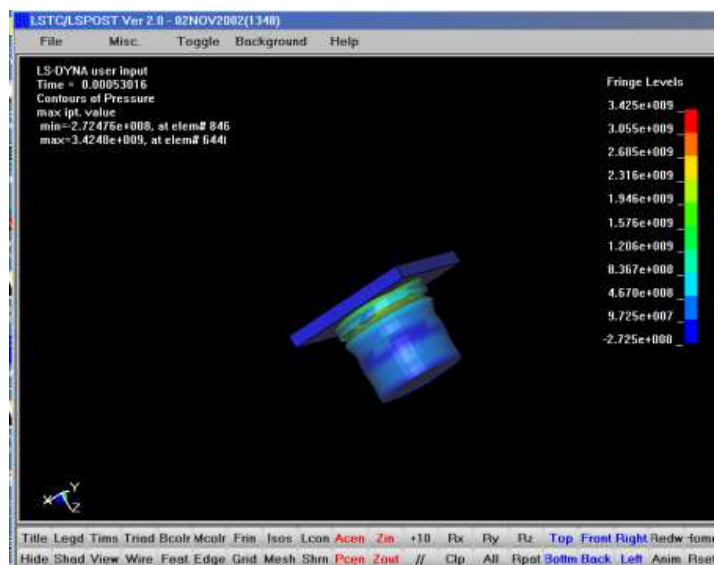

Figure 6: Von mises Stress 


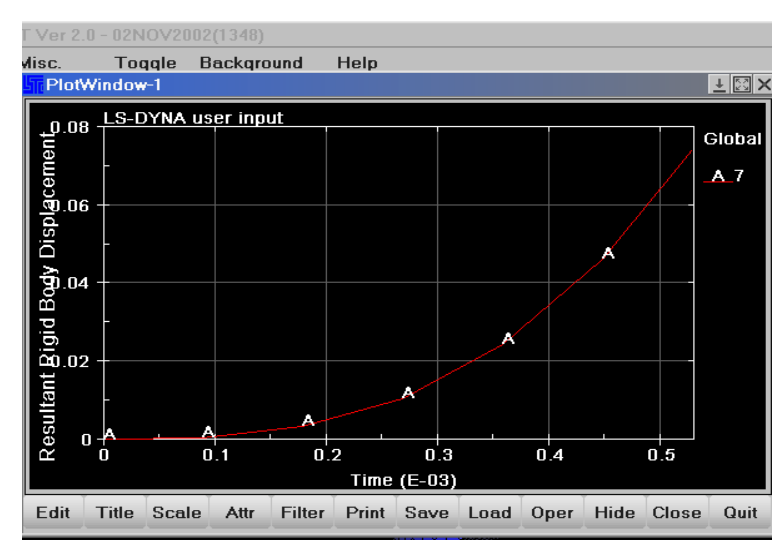

Figure 7: Showing Z -Stress Plot

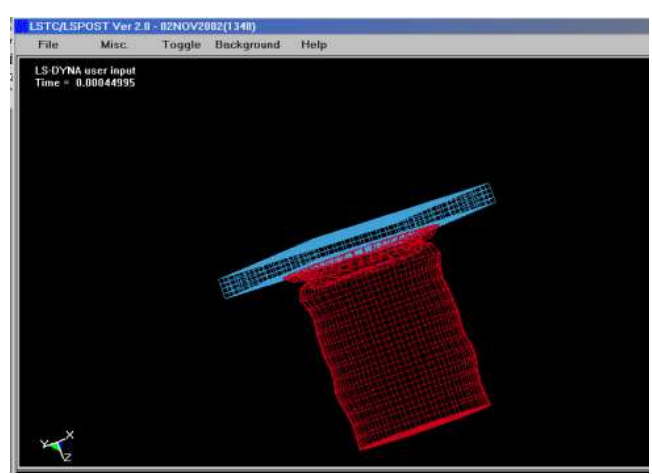

Figure 9: Initial Crush of the Can

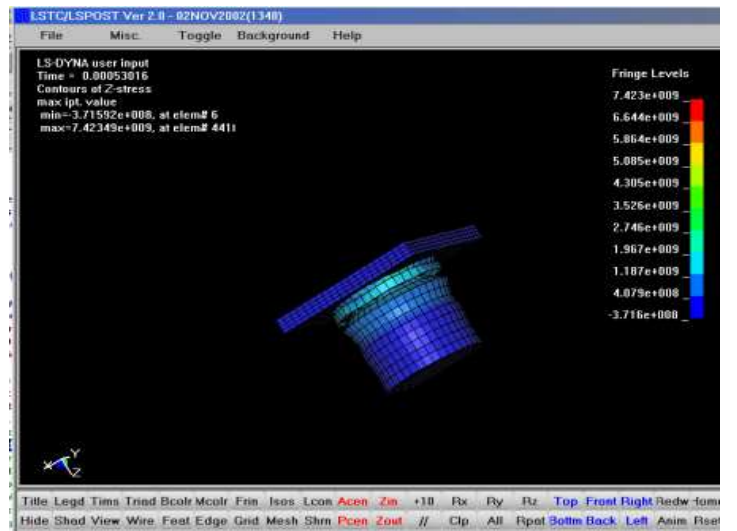

Figure 8: Showing Resultant Displacement

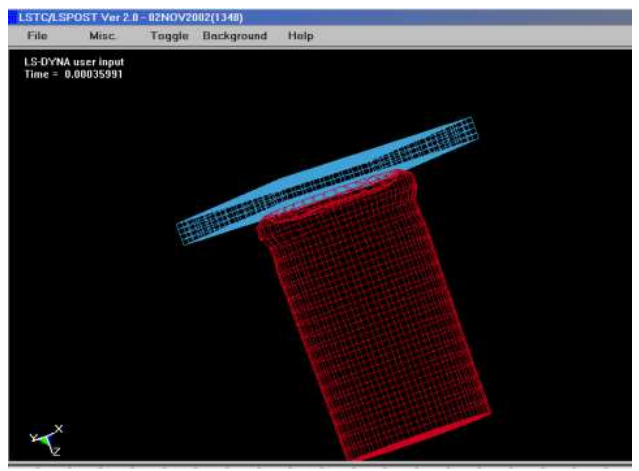

Figure 10: Crush at the Centre of the Can

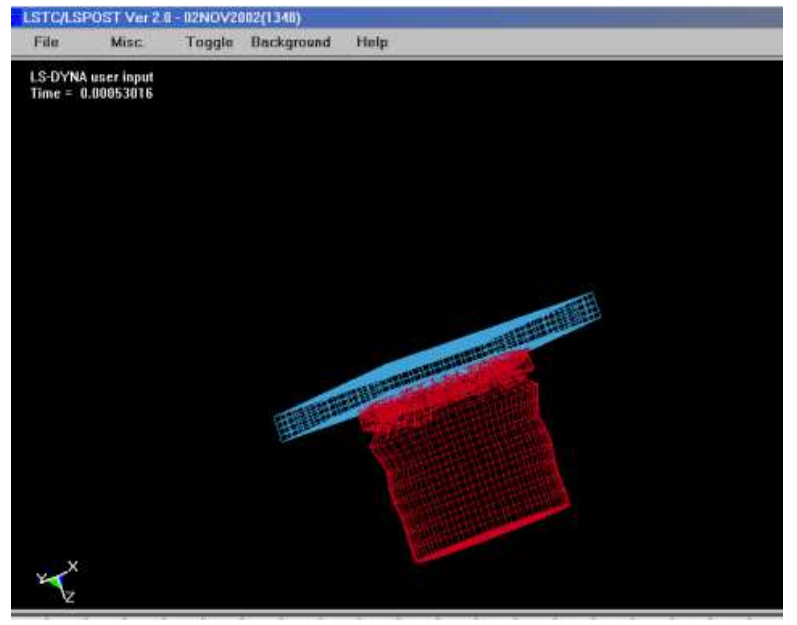

Figure 11: Final Crush of the Can

\section{CONCLUSIONS}

The double toggle mechanism is implemented successfully in the can crushing operation. The purpose is to transport rotational movement of the motor into just before and fro movement so increase input weight (as a toggle device afford the essential mechanical benefit), and locking the position of a linkage allowing the can to buckle realistically. The width of the Can lid is ready in such a means that part of it lies down over neutral axis and the last part is under it, this might have stiffened the lid of the can. This could be a precursor for crushing of Soda Cans. Finally the numerical simulation was carried out by using commercial available CFD software named Ansys and results are presented for the 
crushing operation. Ultimately, a double toggle mechanism is made upto demonstrate the possibility of the future model and crushing of the canusing the mechanism.

\section{ACKNOWLEDGEMENT}

Author thanks the management of Sri Venkateswara College of Engineering for providing the experimental setup to do this work.

\section{REFERENCES}

1. LIAO HanYuan, KUN JianYi, NIU GuoHui, Jawcrusher, Beijing, China Machine Press, 1998 (in Chinese).

2. Tiger Studios, Tong Heting. Pro/ENGINEER Wildfire 4.0 Kinematic simulation and dynamic analysis. Beijing: People's Posts and Telecommunications Press .2009(in Chinese).

3. Mechanical operations by Anup K Swain, Hemlata Patra, \& G K Roy

4. Taggart, Arthu F “ Hand book of ore dressing” Tohn Willey \& Sons inc. 1998

5. Yun, K., Hirano, M., Yanase, S., \& Ohya, Y. (2016). New Fabrication Method Suggestion of the Motor Core Using Ceramic Precursor.

6. Liao Hanyuan, Jian yi, Niu Guohui. Crusher. Beijing: Mechanical Industry Press. (1998), pp.1-3(in chinese)

7. R.S Khurmi and J.K Gupta: A Textbook of Machine Design, 1st Multi-colour edition, S. Chand and Company Ltd., New Delhi, 2005 .

8. Shigley's Mechanical Engineering Design, 8th Edition, Mc Graw-Hill Book company, New York, 2007 5. Kimbrell J.T: Kinematics Analysis and Synthesis by McGraw-Hills Book company, 1st edition, New York, 1991 